\title{
Natural history of brainstem cavernous malformations: prospective hemorrhage rate and adverse factors in a consecutive prospective cohort
}

\author{
*Da Li, MD, ${ }^{1}$ Ze-Yu Wu, MD, ${ }^{1}$ Pan-Pan Liu, MD, ${ }^{1,2}$ Jun-Peng Ma, MD, ${ }^{1}$ Xu-Lei Huo, MD, ${ }^{1}$ \\ Liang Wang, MD, PhD, ${ }^{1}$ Li-Wei Zhang, MD, PhD, ${ }^{1}$ Zhen Wu, MD, PhD, ${ }^{1}$ and Jun-Ting Zhang, MD ${ }^{1}$ \\ 1Department of Neurosurgery, Beijing Tiantan Hospital, Capital Medical University, Beijing; and 2Department of Neurosurgery, \\ The Municipal Hospital of Weihai, People's Republic of China
}

OBJECTIVE Given the paucity of data on the natural history of brainstem cavernous malformations (CMs), the authors aimed to evaluate the annual hemorrhage rate and hemorrhagic risk of brainstem CMs.

METHODS Nine hundred seventy-nine patients diagnosed with brainstem CMs were referred to Beijing Tiantan Hospital from 2006 to 2015; 224 patients were excluded according to exclusion criteria, and 47 patients were lost to follow-up. Thus, this prospective observational cohort included 708 cases ( 324 females). All patients were registered, clinical data were recorded, and follow-up was completed.

RESULTS Six hundred ninety (97.5\%) of the 708 patients had a prior hemorrhage, $514(72.6 \%)$ had hemorrhagic presentation, and developmental venous anomaly (DVA) was observed in 241 cases (34.0\%). Two hundred thirty-seven prospective hemorrhages occurred in 175 patients $(24.7 \%)$ during 3400.2 total patient-years, yielding a prospective annual hemorrhage rate of $7.0 \%(95 \% \mathrm{Cl} 6.2 \%-7.9 \%)$, which decreased to $4.7 \%$ after the 1 st year. Multivariate Cox regression analysis after adjusting for sex and age identified hemorrhagic presentation (HR 1.574, $p=0.022$ ), DVA (HR 1.678, $p=0.001$ ), $m R S$ score $\geq 2$ on admission (HR 1.379, $p=0.044$ ), lesion size $>1.5 \mathrm{~cm}$ (HR 1.458, $p=0.026)$, crossing the axial midpoint (HR 1.446, $p=0.029$ ), and superficially seated location (HR 1.307, $p=0.025$ ) as independent adverse factors for prospective hemorrhage, but history of prior hemorrhage was not significant. The annual hemorrhage rates were $8.3 \%$ and $4.3 \%$ in patients with and without hemorrhagic presentation, respectively; the rate was $9.9 \%, 6.0 \%$, and $1.0 \%$ in patients with $\geq 2$, only 1 , and 0 prior hemorrhages, respectively; and the rate was $9.2 \%$ in patients with both hemorrhagic presentation and focal neurological deficit on admission.

CONCLUSIONS The study reported an annual hemorrhage rate of $7.0 \%$ exclusively for brainstem CMs, which significantly increased if patients presented with both hemorrhagic presentation and focal neurological deficit (9.2\%), or any other risk factor. Patients with a risk factor for hemorrhage needed close follow-up regardless of the number of prior hemorrhages. It should be noted that the referral bias in this study could have overestimated the annual hemorrhage rate. This study improved the understanding of the natural history of brainstem CMs, and the results are important for helping patients and physicians choose a suitable treatment option based on the risk factors and stratified annual rates. Clinical trial registration no.: ChiCTR-POC-17011575 (http://www.chictr.org.cn/).

https://thejns.org/doi/abs/10.3171/2019.12.JNS192856

KEYWORDS brainstem cavernous malformation; cavernoma; cerebral cavernous malformation; hemangioma; natural history; vascular disorders

$\Lambda$ $\mathrm{s}$ the second most common intracranial vascular malformation, ${ }^{37}$ cerebral cavernous malformations (CCMs) are composed of dilated sinusoidal channels, with a population prevalence of $0.4 \%-0.6 \%,{ }^{15}$ approximately $19.1 \%$ (range $11 \%-30 \%$ ) of which involve the brainstem. 1,4,7, 13,15,19,20,28,29,31,32 The natural history of CCMs was extensively evaluated in prior studies, ${ }^{1-4,6-9,11-13,}$ $15-17,19,20,23,24,28,29,31,32$ and particularly elaborated by Al-Shahi Salman et al., ${ }^{3-5,16}$ Flemming et al., ${ }^{9}$ and Gross et al., ${ }^{11-}$ 13,15 but few studies focused on brainstem CMs that were

ABBREVIATIONS $\mathrm{CCM}=$ cerebral $\mathrm{CM} ; \mathrm{CM}=$ cavernous malformation; DVA = developmental venous anomaly; FND = focal neurological deficit; $\mathrm{mRS}=$ modified Rankin Scale; ROC = receiver operating characteristic; SRS = stereotactic radiosurgery.

SUBMITTED October 20, 2019. ACCEPTED December 30, 2019.

INCLUDE WHEN CITING Published online March 13, 2020; DOI: 10.3171/2019.12.JNS192856.

* D.L., Z.Y.W., P.P.L., and J.P.M. contributed equally to this work. 
infrequently and separately reported or simply classified into deep location. There has been no consensus regarding the hemorrhagic predictors of CCMs (except prior hemorrhage), ${ }^{1,49,12,13,15-17,19,20,23,24,29,34}$ but deep, ${ }^{29}$ nonlobar, ${ }^{7}$ and brainstem ${ }^{14,16,33}$ locations have been documented as significant risk factors for rehemorrhage, which was described as one of the top 10 research priorities for CCMs. ${ }^{5}$ Due to the high density of eloquent long-fiber tracts and vital nervous nuclei, the brainstem is vulnerable to hemorrhagic ictus or even minor bleeding that increases the chance of symptomatic hemorrhage with more severe disability compared to supratentorial counterparts. ${ }^{4,16}$ The estimated 5 -year risk for a hemorrhagic event in brainstem CMs presenting with hemorrhage or focal neurological deficit (FND) was $30.8 \%$ in one meta-analysis. ${ }^{16}$ Therefore, we aimed to evaluate the adverse factors and hemorrhage rate of brainstem CMs based on a consecutive prospective cohort over a decade and to provide meaningful evidence for treatment selection.

\section{Methods}

\section{Patient Population}

This prospective cohort included patients with brainstem CMs referred to the outpatient department of Beijing Tiantan Hospital from January 2006 to December 2015. All clinical data were obtained from a prospective clinical trial (registration no. ChiCTR-POC-17011575; http://www. chictr.org.cn/). The Beijing Tiantan Hospital Research Ethics Committee approved this study, and written informed consent was obtained from all patients. The inclusion criteria were definitive diagnosis of a brainstem CM and provision of informed consent. The exclusion criteria included one of the following conditions: 1) prior resection or radiotherapy; 2) severe comorbidities involving the brainstem, peripheral nerves, or other hazardous lobes that might influence the evaluation of neurological function; 3) pregnancy and breastfeeding; 4) refusal to participate in follow-up; or 5) receiving resection immediately after diagnosis at our institute. Stereotactic radiosurgery (SRS) was not recommended in our institute, and the surgical indications have been described in our prior studies as follows: ${ }^{25-27,35} 1$ ) multiple hemorrhages ( $\geq 2$ ictuses), lesion size $\geq 2 \mathrm{~cm}$, and severe or progressive neurological deficit; 2) lesion in the medulla oblongata; 3) acute or subacute hemorrhage with a significant mass effect; or 4) exophytic lesion or one abutting the pial surface accessible via the "safe entry zones."

\section{Diagnosis and Clinical Data Collection}

The patient's chart (sex, age, medical and family history, and other data) was recorded in our electronic medical system (Table 1). Radiological images were extensively reviewed, and 2 neuroradiologists independently reviewed MR images to confirm the diagnosis based on the accepted criteria. ${ }^{30,36}$ Radiographic data included lesion location (depth and side), crossing the axial midpoint, ${ }^{10}$ equivalent size, perilesional edema, Zabramski classification, ${ }^{36}$ and developmental venous anomaly (DVA). The multiple cerebral CMs or brainstem CMs were recorded based on gradient-echo images and/or susceptibility-weighted im- aging. Hemorrhage on admission was noted if an overt intralesional or extralesional hemorrhage was observed on the latest MRI at diagnosis. The prior hemorrhage was determined by the serial radiographic evidence before enrollment, combined with medical records; lesions without prior hemorrhage were usually asymptomatic or diagnosed incidentally due to other unrelated causes. To minimize recall bias, which introduced significant uncertainty, a clinically symptomatic event recalled by patients at enrollment was not considered a hemorrhagic event if it was not substantiated by concomitant radiographs. FND was defined as cranial neuropathy and/or long-tract deficit (motor and sensory deficit) pertinent to the anatomical location of the lesion. Non-FNDs included headache, dizziness, nausea, vomiting, and/or other symptoms not directly associated with the lesion. Two authors (Z.Y.W. and P.P.L.), blinded to radiographs and hemorrhagic status, evaluated neurological function using a modified Rankin Scale (mRS) score and completed the scheduled followup, with any discrepancies resolved by the senior author (J.T.Z).

\section{Follow-Up and Statistical Analysis}

The inception point of enrollment in the study was the diagnosis of brainstem CM at our institute. Follow-up was performed at 3,6 , and 12 months after diagnosis and then annually afterward (via clinical visits, mailed questionnaires, telephone interviews, and/or contact with the family doctor), and MRI scans were recommended on the same schedule. Data were acquired, including treatment since enrollment inception, treatment effects, changes in neurological status, and mRS score. Prospective hemorrhage was defined as a clinically symptomatic event (acute or subacute, new onset or worsening of an FND, or severe headache) corresponding to the anatomical location of the brainstem CM, with the overt hemorrhage within or outside the lesion, and change in lesion size and signal intensity based on comparison of radiographs obtained at various periods. ${ }^{3,4,23} \mathrm{~A}$ hemorrhagic event was uncertain if a clinical event was suspicious without concomitant radiological evidence. An asymptomatic hemorrhage was defined as an overt hemorrhage with a change in lesion size and signal intensity but without a clinical event. Radiological examination was required following a questionable clinical event or hemorrhage to verify the hemorrhagic ictus.

The prospective annual hemorrhage rate was calculated as the number of hemorrhages divided by the duration (in years) of follow-up per patient and was further stratified by the adverse factors for hemorrhage (Table 2). Hemorrhage-free survival duration began at enrollment and ended on the date of the earliest rehemorrhage or the date of censoring (surgery, SRS, death, or most recent evaluation), whichever occurred first. The cutoff value of lesion size was determined using a receiver operating characteristic (ROC) curve. The hemorrhagic risk factors were evaluated by univariate Cox proportional hazards regression, and all univariate significant risk factors together with age and sex were entered into the multivariate Cox regression to confirm the independent risk factors. Survival curves were illustrated by the Kaplan-Meier method (univariate survival analysis). The analyses were performed us- 
TABLE 1. Demographics of patients with brainstem CMs: total and stratified by number of prospective hemorrhages

\begin{tabular}{|c|c|c|c|c|c|}
\hline Variable (\%) & Overall, $n=708$ & No Ictus, $n=533$ & 1 Ictus, $n=132$ & $>1$ lctus, $n=43$ & $\mathrm{p}$ Value \\
\hline Female, $\mathrm{n}(\%)$ & $324(45.8)$ & $244(45.8)$ & $61(46.2)$ & $19(44.2)$ & $0.973^{*}$ \\
\hline Mean age on admission (median), yrs & $38.2(38.0)$ & $37.8(38.0)$ & $40.4(40.5)$ & $36.8(39.0)$ & $0.112 \dagger$ \\
\hline Hypertension, $n(\%)$ & $96(13.6)$ & $74(13.9)$ & $15(11.4)$ & $7(16.3)$ & $0.650^{*}$ \\
\hline Mean duration of symptoms (median), mos & $21.5(2.7)$ & $20.6(2.4)$ & $23.5(4.0)$ & $26.1(3.1)$ & $0.623 \dagger$ \\
\hline Patients w/ prior hemorrhages, $\mathrm{n}(\%)$ & $690(97.5)$ & $516(96.8)$ & $131(99.2)$ & $43(100.0)$ & $0.156^{*}$ \\
\hline Overall no. of prior hemorrhages & 1021 & 743 & 203 & 75 & \\
\hline Mean no. of prior hemorrhages (median) & $1.4(1.0)$ & $1.4(1.0)$ & $1.5(1.0)$ & $1.7(1.0)$ & $0.008 \dagger$ \\
\hline Cumulative yrs of life & 27,049 & 20,131 & 5335 & 1583 & \\
\hline Retrospective annual hemorrhage rate, $\%$ & 3.8 & 3.7 & 3.8 & 4.7 & \\
\hline Mean mRS score on admission (median) & $1.6(1.0)$ & $1.6(1.0)$ & $1.7(1.0)$ & $1.8(1.0)$ & $0.325 t$ \\
\hline Hemorrhage on admission, $\mathrm{n}(\%)$ & $514(72.6)$ & $375(70.4)$ & $104(78.8)$ & $35(81.4)$ & $0.062^{*}$ \\
\hline FND on admission, $\mathrm{n}(\%)$ & $580(81.9)$ & $426(79.9)$ & $115(87.1)$ & $39(90.7)$ & $0.048^{*}$ \\
\hline Hemorrhage + FND on admission, $n(\%)$ & $442(62.4)$ & $314(58.9)$ & $96(72.7)$ & $32(74.4)$ & $0.003^{*}$ \\
\hline CM location, $\mathrm{n}(\%)$ & & & & & $0.567^{*}$ \\
\hline Midbrain & $155(21.9)$ & $110(20.6)$ & $34(25.8)$ & $11(25.6)$ & \\
\hline Pons & $447(63.1)$ & $344(64.5)$ & $76(57.6)$ & $27(62.8)$ & \\
\hline Medulla & $106(15.0)$ & $79(14.8)$ & $22(16.7)$ & $5(11.6)$ & \\
\hline Crossing axial midpoint, $\mathrm{n}(\%)$ & $176(24.9)$ & $122(22.9)$ & $45(34.1)$ & $9(20.9)$ & $0.024^{*}$ \\
\hline DVA, $\mathrm{n}(\%)$ & $241(34.0)$ & $162(30.4)$ & $57(43.2)$ & $22(51.2)$ & $0.001^{*}$ \\
\hline Multiple CCMs, n (\%) & $92(13.0)$ & $63(11.8)$ & $18(13.6)$ & $11(25.6)$ & $0.035^{\star}$ \\
\hline Multiple brainstem CMs, n (\%) & $61(8.6)$ & $41(7.7)$ & $12(9.1)$ & $8(18.6)$ & $0.048^{*}$ \\
\hline Perilesional edema, n (\%) & $344(48.6)$ & $260(48.8)$ & $65(49.2)$ & $19(44.2)$ & $0.834^{*}$ \\
\hline Zabramski classification, n (\%) & & & & & $0.305^{\star}$ \\
\hline I & $192(27.1)$ & $140(26.3)$ & 41 (31.1) & $11(25.6)$ & \\
\hline II & $330(46.6)$ & $243(45.6)$ & $63(47.7)$ & $24(55.8)$ & \\
\hline III/IV & $186(26.3)$ & $150(28.1)$ & $28(21.2)$ & $8(18.6)$ & \\
\hline Mean lesion size (median), cm & $1.5(1.4)$ & $1.5(1.4)$ & $1.6(1.7)$ & $1.6(1.6)$ & $0.047 \dagger$ \\
\hline Side, $n(\%)$ & & & & & $0.759^{*}$ \\
\hline Lateral & $183(25.8)$ & $144(27.0)$ & $30(22.7)$ & $9(20.9)$ & \\
\hline Ventral & $218(30.8)$ & $161(30.2)$ & $44(33.3)$ & $13(30.2)$ & \\
\hline Dorsal & $307(43.4)$ & $228(42.8)$ & $58(43.9)$ & $21(48.8)$ & \\
\hline Depth, n (\%) & & & & & $0.125^{*}$ \\
\hline Superficial & $402(56.8)$ & $288(54.0)$ & $87(65.9)$ & $27(62.8)$ & \\
\hline Moderate & $210(29.7)$ & $166(31.1)$ & $33(25.0)$ & $11(25.6)$ & \\
\hline Deep & $96(13.6)$ & $79(14.8)$ & $12(9.1)$ & $5(11.6)$ & \\
\hline Disease-specific death, $\mathrm{n}(\%)$ & $13(1.8)$ & 0 & $11(8.3)$ & $2(4.7)$ & $<0.001^{*}$ \\
\hline Patients receiving surgery, $\mathrm{n}(\%)$ & $173(24.4)$ & $110(20.6)$ & $48(36.4)$ & $15(34.9)$ & $<0.001^{*}$ \\
\hline Patients receiving SRS, $\mathrm{n}(\%)$ & $15(2.1)$ & $8(1.5)$ & $5(3.8)$ & $2(4.7)$ & \\
\hline
\end{tabular}

Boldface type indicates statistical significance.

${ }^{*}$ Chi-square test.

$\dagger$ One-way ANOVA.

$\ddagger$ Kruskal-Wallis test.

ing IBM SPSS statistical package software (version 25.0; IBM Corp.) with the significance set at $\mathrm{p}<0.05$ and using confidence interval (CI) analysis software.

\section{Results}

\section{Patient Demographics}

During the 10 years, 979 patients diagnosed with brain- stem CMs were referred to our institute, and 224 patients were excluded due to the study exclusion criteria, including 125 patients receiving resection immediately after diagnosis (Fig. 1). The prospective cohort included 755 patients, and $47(6.2 \%)$ were lost to follow-up after enrollment. In 708 patients (324 females, 45.8\%) with available followup, the mean and median ages on admission were 38.2 and 38.0 years (range 3-76 years), respectively, with a mean 
Li et al.

TABLE 2. Annual rate of prospective hemorrhage stratified by risk factors in patients with brainstem CMs

\begin{tabular}{|c|c|c|c|c|c|c|c|}
\hline \multirow[b]{2}{*}{ Risk Factor } & \multicolumn{7}{|c|}{ Years } \\
\hline & 0 to $<0.5$ & 0.5 to $<1$ & 0 to $<1$ & 1 to $<2$ & 2 to $<5$ & 5 to $<10$ & Overall \\
\hline Overall & $21.8(17.4-26.9)$ & $13.0(9.4-17.6)$ & $17.5(14.6-20.9)$ & $7.2(5.3-9.8)$ & $4.8(3.8-6.1)$ & $2.9(1.9-4.4)$ & $7.0(6.2-7.9)$ \\
\hline DVA & $34.7(25.7-44.7)$ & $17.0(10.3-26.5)$ & $26.3(20.4-33.1)$ & $9.9(6.1-15.4)$ & $6.4(4.5-9.2)$ & $4.5(2.5-7.8)$ & $10.1(8.4-12.1)$ \\
\hline No DVA & $15.2(10.7-21.0)$ & $11.0(7.1-16.5)$ & $13.2(10.1-17.0)$ & $5.9(3.8-9.0)$ & $4.1(3.0-5.6)$ & $2.2(1.2-3.9)$ & $5.5(4.6-6.5)$ \\
\hline mRS score 2 on admission & $32.6(23.7-43.0)$ & $17.6(10.5-27.8)$ & $25.6(19.6-32.7)$ & $10.4(6.3-16.3)$ & $5.3(3.4-8.0)$ & $5.4(3.2-9.1)$ & $9.8(8.1-11.9)$ \\
\hline $\mathrm{mRS}<2$ on admission & $16.7(12.0-22.6)$ & $11.0(7.2-16.4)$ & $13.9(10.8-17.8)$ & $5.9(3.9-8.9)$ & $4.6(3.5-6.2)$ & $1.8(0.9-3.4)$ & $5.8(4.9-6.8)$ \\
\hline Hemorrhage on admission & $28.2(22.5-35.0)$ & $14.6(10.1-20.7)$ & $21.8(17.9-26.2)$ & $7.9(5.4-11.2)$ & $5.7(4.4-7.4)$ & $3.2(1.9-5.1)$ & $8.3(7.2-9.5)$ \\
\hline No hemorrhage on admission & $7.4(3.3-15.1)$ & $9.6(4.7-17.8)$ & $8.5(5.1-13.6)$ & $6.0(3.2-10.7)$ & $3.1(1.8-5.1)$ & $2.3(0.9-5.2)$ & $4.3(3.2-5.7)$ \\
\hline Size $>1.5 \mathrm{~cm}$ & $35.1(26.6-44.7)$ & $13.5(7.7-22.4)$ & $25.2(19.6-31.7)$ & $10.4(6.6-16.1)$ & $7.7(5.5-10.7)$ & $7.1(4.4-11.1)$ & $11.3(9.5-13.4)$ \\
\hline Size $1.5 \mathrm{~cm}$ & $13.9(9.5-19.8)$ & $12.7(8.5-18.5)$ & $13.4(10.2-17.3)$ & $5.7(3.6-8.7)$ & $3.5(2.5-4.9)$ & $0.9(0.3-2.3)$ & $4.9(4.1-5.9)$ \\
\hline Crossing axial midpoint & $39.8(28.7-52.4)$ & $19.1(10.6-31.3)$ & $30.1(22.6-38.7)$ & $9.4(5.0-16.4)$ & $4.6(2.6-7.8)$ & $2.9(1.1-7.0)$ & $9.6(7.6-12.1)$ \\
\hline Not crossing axial midpoint & $16.4(12.1-21.9)$ & $11.2(7.6-16.4)$ & $13.9(11.0-17.5)$ & $6.7(4.6-9.6)$ & $4.9(3.8-6.4)$ & $2.9(1.8-4.6)$ & $6.2(5.4-7.3)$ \\
\hline$>1$ prior ictus & $26.9(18.5-37.2)$ & $19.3(11.8-29.7)$ & $23.3(17.4-30.4)$ & $10.7(6.5-16.8)$ & $6.5(4.4-9.5)$ & $4.9(2.6-8.9)$ & $9.9(8.1-12.0)$ \\
\hline 1 prior ictus & $20.4(15.2-26.7)$ & $10.9(7.0-16.4)$ & $15.8(12.4-19.8)$ & $5.9(3.8-8.9)$ & $4.4(3.2-5.9)$ & $2.2(1.2-3.8)$ & $6.0(5.1-7.1)$ \\
\hline No prior ictus & 0 & 0 & 0 & $5.6(0.3-29.4)$ & 0 & 0 & $1.0(0.1-6.2)$ \\
\hline Hemorrhage + FND & $31.1(24.6-38.5)$ & $15.5(10.5-22.2)$ & $23.7(19.4-28.7)$ & $8.7(5.9-12.5)$ & $6.3(4.8-8.3)$ & $3.5(2.0-5.8)$ & $9.2(8.0-10.6)$ \\
\hline Either hemorrhage or FND & $10.0(5.2-18.1)$ & $12.5(6.9-21.3)$ & $11.3(7.3-16.7)$ & $4.3(2.0-8.6)$ & $2.8(1.6-4.8)$ & $2.6(1.2-5.3)$ & $4.4(3.3-5.7)$ \\
\hline Neither hemorrhage nor FND & $3.6(0.2-20.2)$ & 0 & $1.8(0.1-10.8)$ & $9.0(3.4-20.5)$ & $3.5(1.3-8.4)$ & 0 & $3.5(1.9-6.3)$ \\
\hline
\end{tabular}

The annual rate of prospective hemorrhage was stratified by the risk factors during the specified yearly intervals. The period " 0 to $<0.5$ " refers to the first 6 -month interval since the inception; " 0.5 to $<1$ " refers to the second 6 -month interval since the inception; " 0 to $<1$ " refers to the 1st year interval since the inception; and " 1 to $<2$," " 2 to $<5$," and " 5 to $<10$ " refer to the interval of the 2 nd year, the interval from the 3 rd year to the 5 th year, and the interval from the 6 th year to the 10 th year, respectively. All data given as percentage $(95 \% \mathrm{Cl})$.

duration of symptoms of 21.5 months (range 1 day-358.5 months). Family history, hypertension, and hemorrhages following occasional alcohol ingestion were recorded in $9(1.3 \%), 96(13.6 \%)$, and $10(1.4 \%)$ patients, respectively.
Overall, 690 patients $(97.5 \%)$ suffered a total of 1021 prior hemorrhages during 27,049 cumulative years of life, and the retrospective annual hemorrhage rate was estimated to be $3.8 \%$ (Table 1). The numbers of prior hemorrhage were

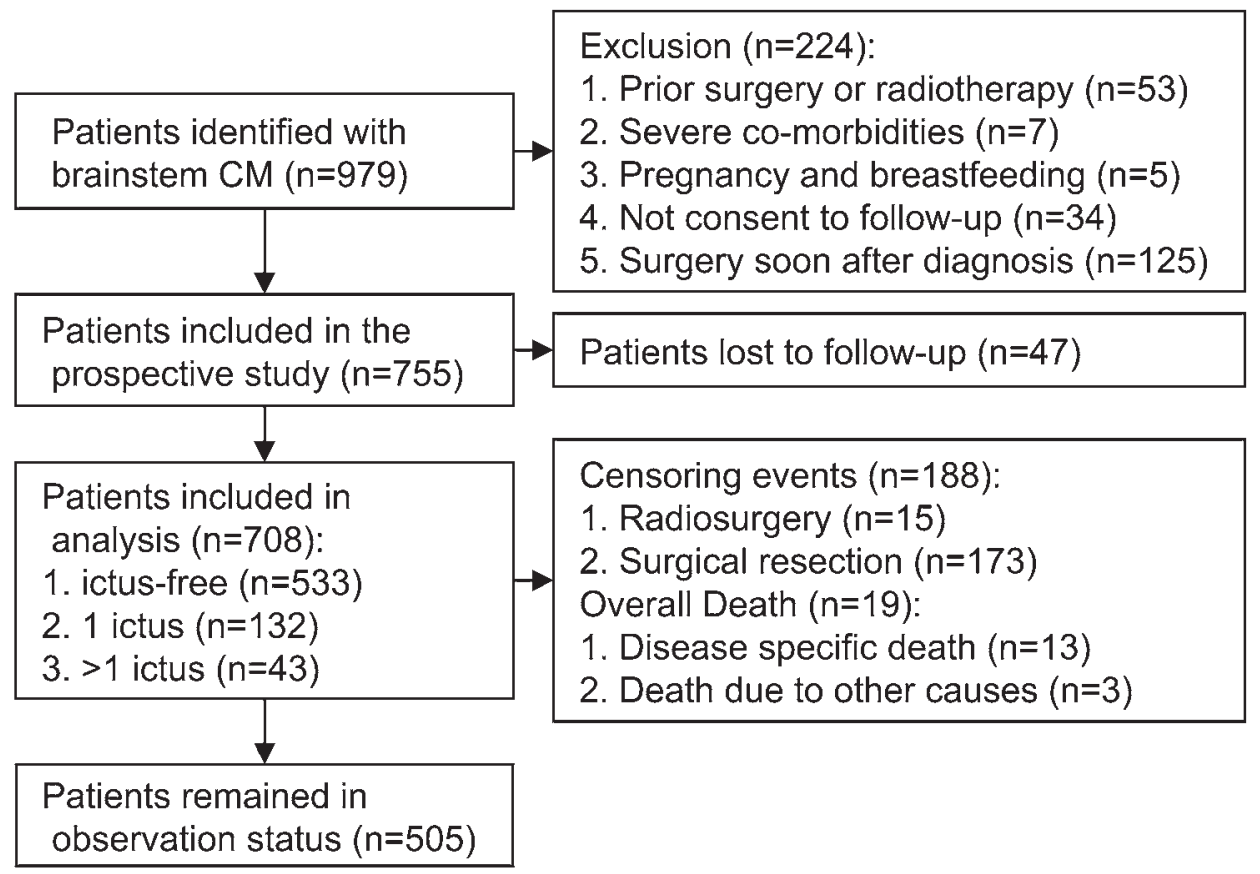

FIG. 1. Patient flow diagram showing the inclusion and exclusion process for the analysis. 

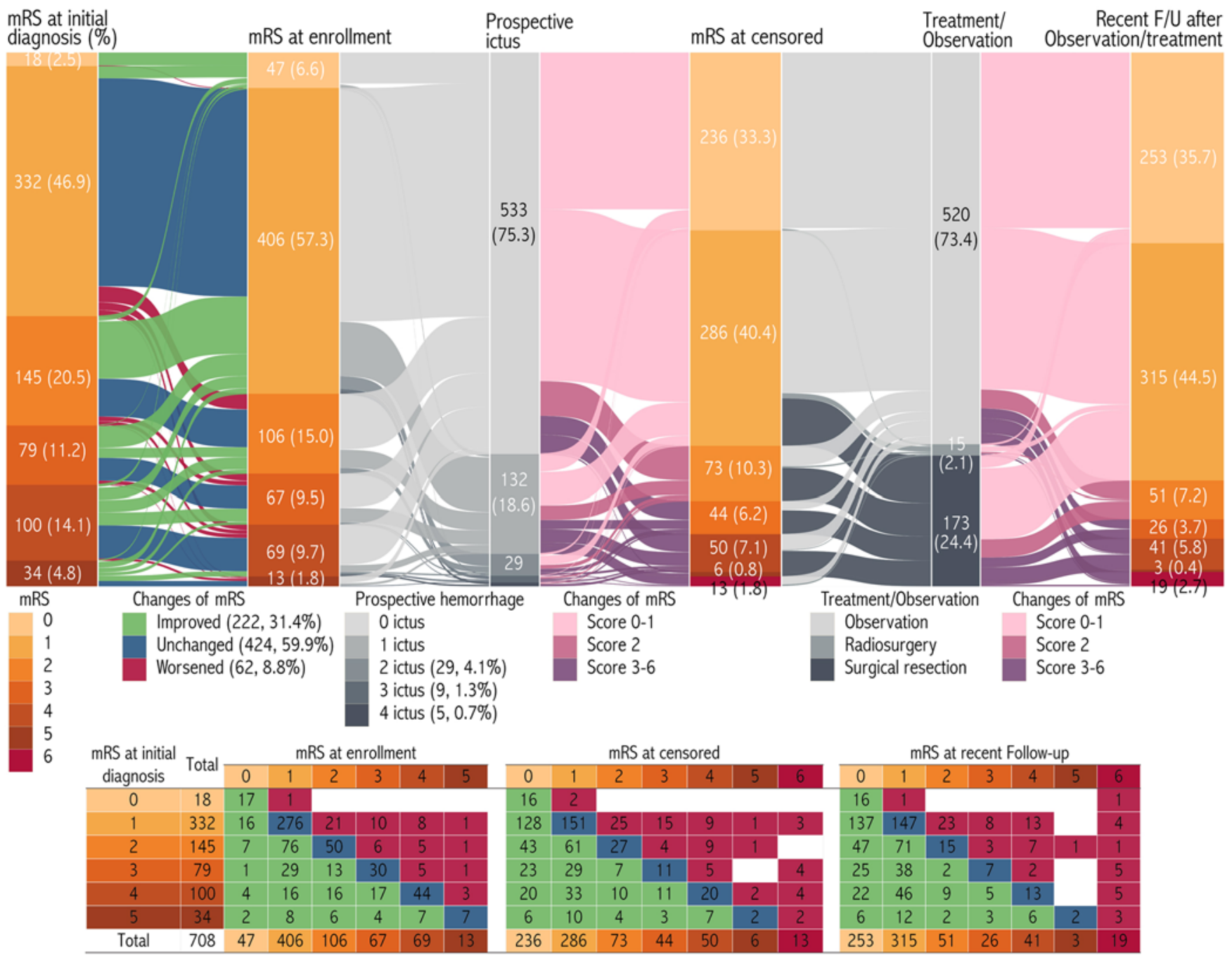

FIG. 2. Sankey diagram showing the distribution and changes of $\mathrm{mRS}$ scores at different periods. Most mRS scores gradually improved during the follow-up period, and some worsened due to rehemorrhage. The horizontal axis of the figure was the time of follow-up from the date of initial diagnosis retrospectively to the date of enrollment, the censoring event, and the recent follow-up evaluation prospectively. The figure consists of 6 bars and 5 flows in between. The 4 bars in orange show the distributions of $\mathrm{mRS}$ scores at each time point of neurological evaluation. Both bars in gray show important intermediate events after inception between the date of enrollment and the time of censoring, and between the date of censoring and the recent follow-up evaluation, respectively. The width and value of each flow was calculated according to the sample size showing the dominant or subordinate contributions to the overall flow. The charts below the bars show the transition of the mRS score at different time points, categorized based on the mRS score at initial diagnosis. $F / U=$ follow-up. Figure is available in color online only.

1,2 , and $>2$ in $455(64.3 \%), 165(23.3 \%)$, and $70(9.9 \%)$ patients, respectively, and 18 patients $(2.5 \%)$ did not have prior hemorrhage.

On admission, 514 patients $(72.6 \%)$ presented with acute $(\mathrm{n}=190,26.8 \%)$ or subacute $(\mathrm{n}=324,45.8 \%)$ hemorrhage. FND $(\mathrm{n}=580,81.9 \%)$, including cranial neuropathy $(n=473,66.8 \%)$ and long-tract deficit $(n=435,61.4 \%)$, was the most common symptom, followed by nonspecific symptoms (headache, dizziness, nausea, and vomiting; $\mathrm{n}=$ 198, 28.0\%) and other deficits (ataxia, disequilibrium, dystonia, and tremor) mimicking extrapyramidal symptoms $(\mathrm{n}=180,25.4 \%)$. Seven patients $(1.0 \%)$ were diagnosed incidentally due to brain injury $(n=1)$, intracranial tumor ( $=1)$, or routine health examination $(n=5)$. The mean and median mRS scores were 1.6 and 1.0, respectively (Fig. 2).

\section{Radiological Characteristics}

The pons $(\mathrm{n}=447,63.1 \%)$ was the predominant $\mathrm{CM}$ location, followed by the midbrain $(\mathrm{n}=155,21.9 \%)$ and medulla $(\mathrm{n}=106,15.0 \%$; Table 1$)$. The mean lesion size was $1.5 \mathrm{~cm}$ (range $0.2-4.0 \mathrm{~cm}$ ). Multiple CCMs, multiple brainstem CMs, and DVAs were observed in 92 (13.0\%), $61(8.6 \%)$, and 241 (34.0\%) patients, respectively; 176 lesions $(24.9 \%)$ were crossing the axial midpoint, and perilesional edema was evident in 344 lesions $(48.6 \%)$ on the latest T2-weighted MR images before enrollment. Most lesions $(\mathrm{n}=307,43.4 \%)$ were dorsally located, and the remaining were either ventral $(\mathrm{n}=218,30.8 \%)$ or lateral (n $=183,25.8 \%)$. Four hundred two lesions $(56.8 \%)$ were superficial, 210 (29.7\%) were moderate, and 96 (13.6\%) were deep seated. The Zabramski classification types I, II, and 


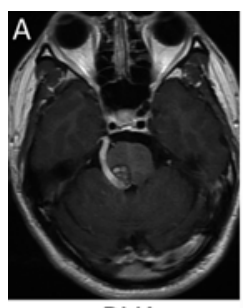

DVA

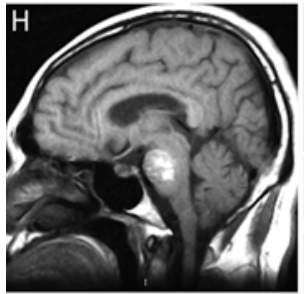

$1^{\text {st }}$ ictus

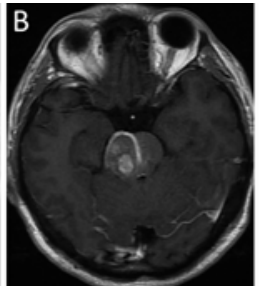

DVA

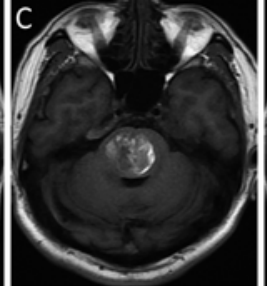

Crossing axial midpoint Yes

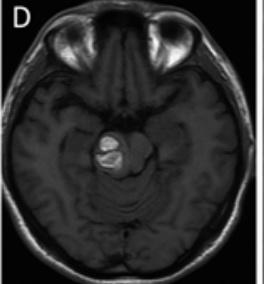

No

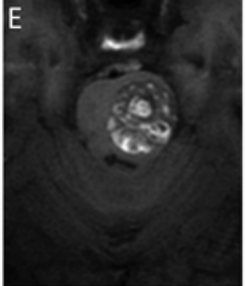

Superficial

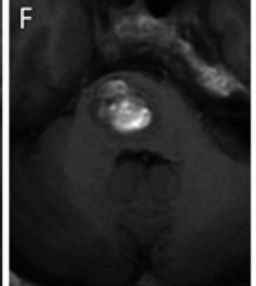

Moderate

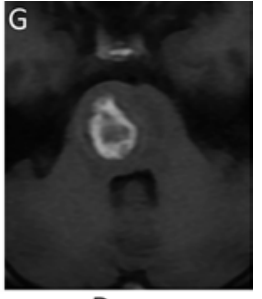

Deep

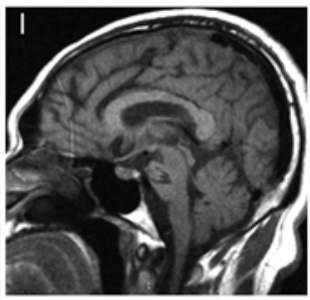

at 20 mos

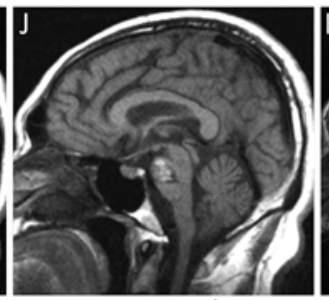

at 25 mos: $2^{\text {nd }}$ ictus

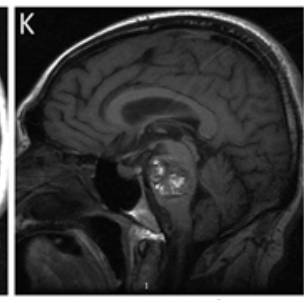

at 26 mos: $3^{\text {rd }}$ ictus

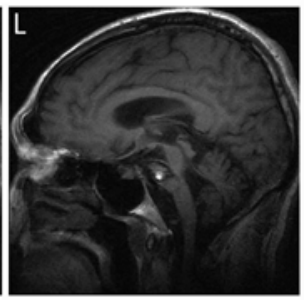

at 53 mos

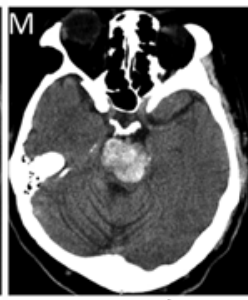

at 60 mos: $4^{\text {th }}$ ictus

FIG. 3. Radiographic characteristics of brainstem CMs. A and B: Both contrast-enhanced T1-weighted axial MR images show associated DVAs. C and D: Axial T1-weighted MR images show 1 lesion (C) crossing the axial midpoint, but not the other (D). E-G: Axial T1-weighted MR images demonstrating the depth of the lesion according to the thickness of the parenchyma between the lesion and the pial/ependymal membrane, as follows: superficial = 1 lesion abutting the pial/ependymal membrane with a thickness of the parenchyma $<1 \mathrm{~mm}(E)$; moderate = thickness of the parenchyma was $1-2 \mathrm{~mm}(F)$; and deep = thickness of the parenchyma was > $2 \mathrm{~mm}(\mathrm{G})$. $\mathrm{H}-\mathrm{M}$ : Case illustration of sagittal T1-weighted MR images $(\mathrm{H}-\mathrm{L})$ and an axial CT scan (M) showing a patient suffering 3 repeat hemorrhages within 60 months since the first ictus, with a stepwise decline in neurological function.

The lesion size experienced repeated decreases followed by increases due to the vanishing of the hematoma and rehemorrhage.

III/IV were noted in 192 (27.1\%), 330 (46.6\%), and 186 (26.3\%) lesions, respectively (Table 1, Fig. 3 ).

\section{Follow-Up}

The mean and median follow-up durations were 57.6 and 61.2 months (range 0.2-152.9 months), respectively, and MRI reexaminations during follow-up were available in 619 patients $(87.4 \%)$. Overall, 15 patients $(2.1 \%)$ received SRS due to rehemorrhage $(n=7)$, poor neurological status $(\mathrm{n}=5)$, and unknown reasons $(\mathrm{n}=3)$, and 5 patients received a second SRS. One hundred seventythree patients $(24.4 \%)$ underwent resection primarily due to multiple prior hemorrhages $(n=61)$, severe neuropathy $(n=22)$, large lesion size $(n=24)$, progressively worsened symptoms $(n=3)$, and rehemorrhage $(n=63)$. One patient received a second surgery due to the failure of the first surgery. The baseline and outcomes of patients receiving SRS, surgery, or observation are detailed in Table 3. The untreated observation interval from the inception of the study to the censoring date in patients receiving SRS or resection was 75.7 months (range 15.8-114.5 months) and 7.9 months (range 0.2-83.4 months), respectively. The mean and median $\mathrm{mRS}$ scores at the time of censoring were 1.2 and 1.0, respectively (range 0-6; score $0, \mathrm{n}=236,33.3 \%$; score $1-2, \mathrm{n}=359,50.7 \%$; score $3-5, \mathrm{n}=100,14.1 \%$; and score $6, \mathrm{n}=13,1.8 \%$; Fig. 2). Compared to $\mathrm{mRS}$ score on admission, the scores of 297 patients $(41.9 \%)$ improved, $336(47.5 \%)$ were unchanged, and $75(10.6 \%)$ worsened. Nineteen patients $(2.7 \%)$ died of rehemorrhage $(n=13$, $1.8 \%)$, other unrelated causes $(\mathrm{n}=3,0.4 \%)$, and unknown causes $(\mathrm{n}=3,0.4 \%)$. The disease-specific survival at 1 , 3,5 , and 10 years was $98.6 \%, 98.0 \%, 97.8 \%$, and $97.4 \%$, respectively.

\section{Prospective Hemorrhage and Risk Factors}

A total of 237 prospective hemorrhages occurred in 175 patients $(24.7 \%)$ during 3400.2 total patient-years (1 ictus, $n=132 ; 2$ ictuses, $n=29 ; 3$ ictuses, $n=9 ; 4$ ictuses, $\mathrm{n}=5$ ) yielding a prospective annual hemorrhage rate of $7.0 \%$ (95\% CI 6.2\%-7.9\%) per patient-year (Table 2). Forty-three patients $(6.1 \%)$ experienced multiple hemorrhages ( $\geq 2$ ictuses). Overall, 104 (43.9\%) and 144 (60.8\%) hemorrhages occurred within 1 and 2 years after enrollment, respectively; for the first hemorrhage $(n=175), 89$ $(50.9 \%)$ and $118(67.4 \%)$ hemorrhages occurred within 1 and 2 years. The mean intervals from the date of inception to the first ictus, from the first to the second ictus, and from the second to the third ictus were 18.7, 14.9, and 12.0 months, respectively. The overall hemorrhage-free survival estimated by Kaplan-Meier analysis at 6 months and at $1,3,5$, and 10 years was $90.4 \%, 86.1 \%, 75.9 \%, 72.3 \%$, and $68.7 \%$. The annual hemorrhage rates during the first and the second 6 months were $21.8 \%$ (total 67 ictuses occurring in 62 patients divided by 307.6 patient-years; $95 \%$ CI $17.4 \%-26.9 \%$ ) and $13.0 \%$ (95\% CI 9.4\%-17.6\%; Table 2 ), which decreased greatly over time to $4.7 \%$ (95\% CI 4.0\%-5.6\%; 133 ictuses during 2807.5 patient-years) after the 1st year. These rates were reflective of significant radiographic hemorrhage.

Regarding the clinical baseline, compared to patients with $<2$ prospective ictuses (Table 1), patients with $\geq 2$ prospective ictuses had significantly more prior hemorrhages $(p=0.008)$, larger lesion size $(p=0.047)$, and a higher proportion of FND on admission $(\mathrm{p}=0.048)$ and DVAs $(p=0.001)$. In the univariate Cox regression analysis (Fig. 4), prior ictus ( $p<0.001)$, DVA ( $<<0.001)$, mRS score $\geq 2$ on admission ( $p<0.001)$, FND on admission ( $p$ 
TABLE 3. Patient demographics categorized by treatment/observation during follow-up

\begin{tabular}{|c|c|c|c|c|}
\hline Variable (\%) & Observation, $n=520$ & SRS, $n=15$ & Surgery, $n=173$ & p Value \\
\hline Female, n (\%) & $239(46.0)$ & $6(40.0)$ & $79(45.7)$ & $0.900^{*}$ \\
\hline Mean age on admission (median), yrs & $39.2(39.5)$ & $41.5(45.0)$ & $34.9(35.0)$ & $0.001 \uparrow$ \\
\hline Patients w/ prior hemorrhages, $n(\%)$ & $502(96.5)$ & $15(100.0)$ & $173(100.0)$ & $0.035^{*}$ \\
\hline Mean no. of prior hemorrhages (median) & $1.4(1.0)$ & $1.5(1.0)$ & $1.7(1.0)$ & $<0.001 \dagger$ \\
\hline Overall no. of prior hemorrhages & 706 & 22 & 293 & \\
\hline Cumulative yrs of life & 20,389 & 623 & 6037 & \\
\hline Retrospective annual hemorrhage rate, $\%$ & 3.5 & 3.5 & 4.9 & \\
\hline Mean lesion size (median), $\mathrm{cm}$ & $1.4(1.3)$ & $1.6(1.5)$ & $2.0(2.0)$ & $<0.001 \dagger$ \\
\hline Crossing axial midpoint, $\mathrm{n}(\%)$ & $109(21.0)$ & $3(20.0)$ & $64(37.0)$ & $<0.001^{*}$ \\
\hline DVA, n (\%) & $170(32.7)$ & $7(46.7)$ & $64(37.0)$ & $0.340^{*}$ \\
\hline Superficial seated, $\mathrm{n}(\%)$ & $272(52.3)$ & $8(53.3)$ & $122(70.5)$ & $<0.001^{*}$ \\
\hline Moderate seated, n (\%) & $163(31.3)$ & $5(33.3)$ & $42(24.3)$ & \\
\hline Deep seated, n (\%) & $85(16.3)$ & $2(13.3)$ & $9(5.2)$ & \\
\hline Hemorrhage on admission, $\mathrm{n}(\%)$ & $344(66.2)$ & $12(80.0)$ & $158(91.3)$ & $<0.001^{*}$ \\
\hline FND on admission, $n(\%)$ & $410(78.8)$ & $15(100.0)$ & $155(89.6)$ & $0.001^{*}$ \\
\hline Mean mRS score on admission (median) & $1.5(1.0)$ & $2.0(1.0)$ & $2.1(2.0)$ & $<0.001 \ddagger$ \\
\hline Mean mRS score at censoring (median) & $0.9(1.0)$ & $1.8(1.0)$ & $2.3(2.0)$ & $<0.001 \ddagger$ \\
\hline Patients w/ prospective hemorrhage, $\mathrm{n}(\%)$ & $105(20.2)$ & $7(46.7)$ & $63(36.4)$ & $<0.001^{*}$ \\
\hline Mean no. of prospective hemorrhages (median) & $0.3(0.0)$ & $0.7(0.0)$ & $0.5(0.0)$ & $0.001 \dagger$ \\
\hline Overall no. of prospective hemorrhages & 146 & 10 & 81 & \\
\hline Cumulative yrs of observation & 3191.4 & 94.6 & 114.2 & \\
\hline Prospective annual hemorrhage rate, $\%$ & 4.6 & 10.6 & 70.9 & \\
\hline Disease-specific death, $\mathrm{n}(\%)$ & $11(2.1)$ & $2(13.3)$ & 0 & $0.001^{*}$ \\
\hline Mortality, n (\%) & $15(2.9)$ & $2(13.3)$ & $2(1.2)$ & $0.017^{*}$ \\
\hline
\end{tabular}

$=0.005)$, hemorrhage on admission $(\mathrm{p}<0.001)$, size $>1.5$ $\mathrm{cm}(\mathrm{p}<0.001)$, crossing the axial midpoint $(\mathrm{p}=0.003)$, and superficially seated location $(p=0.001)$ significantly predicted prospective hemorrhage. However, in the multivariate Cox regression analysis including all univariate significant risk factors with adjustment for sex and age, DVA (HR 1.678, 95\% CI 1.240-2.269, $\mathrm{p}=0.001)$, mRS score $\geq 2$ on admission (HR 1.379, 95\% CI 1.009-1.886, $\mathrm{p}=0.044$ ), hemorrhage on admission (HR 1.574, 95\% CI $1.068-2.320, \mathrm{p}=0.022)$, lesion size $>1.5 \mathrm{~cm}(\mathrm{HR} 1.458$, $95 \%$ CI $1.046-2.032, \mathrm{p}=0.026$ ), crossing the axial midpoint (HR 1.446, 95\% CI 1.039-2.013, $\mathrm{p}=0.029$ ), and superficially seated location (HR 1.307, 95\% CI 1.034-1.651, $\mathrm{p}=0.025)$ were independent adverse factors for prospective hemorrhage (Fig. 5). Prior ictus $(p=0.230)$ and FND on admission $(\mathrm{p}=0.309)$ were no longer risk factors.

\section{Discussion}

No previous evidence has verified that the hemorrhagic risk factors of brainstem CMs are necessarily similar to those of supratentorial CMs. Even in studies of CCMs, there was a wide spectrum of hemorrhage rates and risk factors due to diverse study designs that remained debat- able. Hemorrhage of brainstem CMs tended to be more symptomatic with low complete functional recovery, ${ }^{23,24}$ would produce considerable neuropathies, and subsequently impair the quality of life. Before the study by $\mathrm{Li}$ et al. ${ }^{23}$ reporting 331 cases of brainstem CMs, there were only 182 total cases enrolled in 8 prior natural history studies, without detailed information. ${ }^{1,4,7,19,21,28,29,31}$ In our series, we mainly focused on symptomatic hemorrhage, because asymptomatic hemorrhage usually cannot be easily detected via scheduled radiographic reexamination (hematoma might vanish within the reexamination interval), the nonhemorrhagic event would be overestimated due to the psychological burden, and the mild nonhemorrhagic event did not justify surgical intervention. From a neurosurgical perspective, an accurate symptomatic hemorrhage rate endorsed by radiology was useful for patient counseling, who eagerly inquired about the hemorrhage risk if presented with symptomatic hemorrhage and/or other risk factors on admission. In our institute, treatment of brainstem CMs was conducted using either resection, or observation until the next hemorrhage accompanied by stepwise neurological decline. To avoid this deterioration, we aimed to qualitatively identify patients who would potentially suffer future hemorrhage based on the risk factors and the 


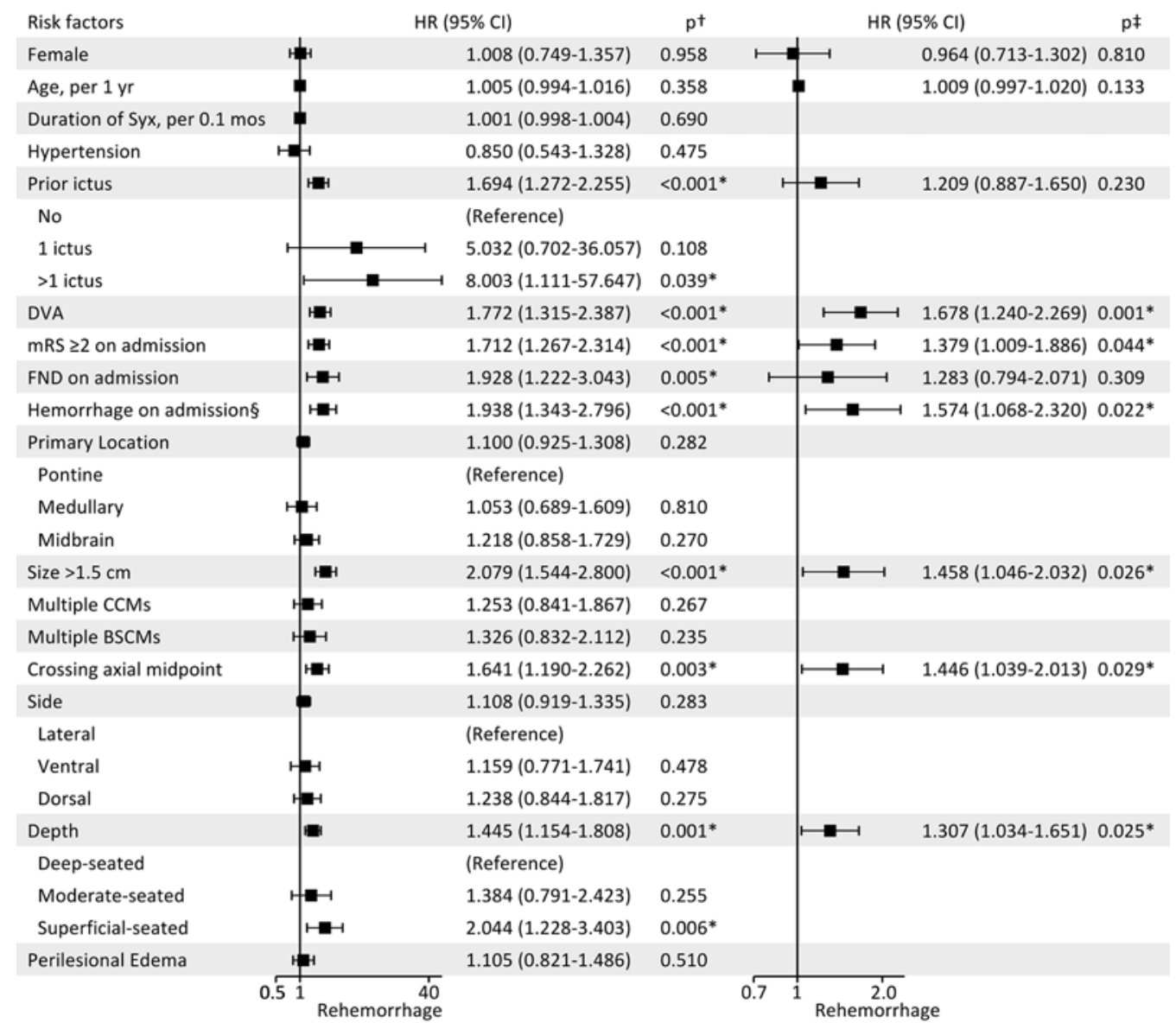

FIG. 4. Forest plot showing HRs for prospective hemorrhage. The black squares indicate the HR values, and error bars represent $95 \%$ Cls. ${ }^{*}<0.05$; †univariate Cox's proportional hazards regression model; łmultivariate Cox's proportional hazards regression model adjusted for age and sex; §Zabramski grade recorded as type I or II. BSCMs = brainstem CMs; Syx = symptoms.

stratified rates (Table 2). Overall, we identified several independent risk factors (Fig. 5), an annual hemorrhage rate of $7.0 \%$ that was within the limits of prior studies, and an acceptable mortality rate of $1.8 \%$, with a disease-specific survival rate at 10 years of $97.4 \%$.

\section{Hemorrhagic Risk Factors}

Both female ${ }^{1,4,23,28,31}$ and male ${ }^{9}$ sex were each once considered risk factors for rehemorrhage, but other studies as well as our cohort failed to identify this significance., ${ }^{70,29}$ There has been speculation about the association between hormone levels and consequent hemorrhage, but this association was questionable due to lack of pathophysiological evidence and the fact that pregnancy did not increase hemorrhage rates. ${ }^{9,18}$ Furthermore, in 3 recent meta-analyses, sex did not add independent prognostic information. . $^{13,16,33}$

Prior hemorrhage had been acknowledged as a lesscontroversial risk factor that has been consistent throughout most studies. ${ }^{4,9,14,17,20,21,23}$ The rehemorrhage risk usually doubled or greatly increased in patients with prior hemorrhage (Jeon et al., ${ }^{17}$ HR 7.13, and Gross et al., ${ }^{14} \mathrm{HR}$ 4.63) or hemorrhagic presentation (Flemming et al., ${ }^{9} \mathrm{HR}$ 5.26) compared to patients without hemorrhage, and the subdivided annual rates without this risk factor were only
$0.33 \%-1.2 \%,{ }^{9,14,34}$ but increased to $6.19 \%-11.7 \%$ if this risk factor was included. ${ }^{9,14,34}$ Aiba et al. ${ }^{1}$ reported a remarkably high annual hemorrhage rate of $22.9 \%$ for patients with prior hemorrhage. Porter et al. ${ }^{29}$ and Moriarity et al..$^{28}$ initially failed to confirm the significance of prior hemorrhage, but the effect of prior hemorrhage became significant in the subgroup analysis if combined with FND presentation $^{29}$ or if restricted to extralesional hemorrhage. ${ }^{21}$ We evaluated both the effect of prior hemorrhage and the effect of hemorrhagic presentation on future hemorrhage, and both were significant in the univariate model (Fig. 4); however, only hemorrhagic presentation remained independently significant in the multivariate model, and the effect of prior hemorrhage was no longer significant, which suggested more statistical validity and weight favoring hemorrhagic presentation, directly reflecting the current hemorrhagic activity and indicating patients' early stage of

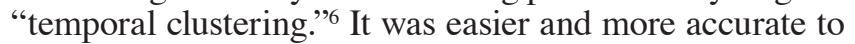
judge the hemorrhagic presentation based on radiographs. Prior hemorrhage, which is subject to recall bias, seemed to be a confounding factor versus hemorrhagic presentation, which might be attributable to the small cohort without prior hemorrhage $(n=18,2.5 \%)$.

DVA has been associated with CM development, ${ }^{13}$ pretreatment hemorrhage, ${ }^{14}$ and postoperative rehemor- 

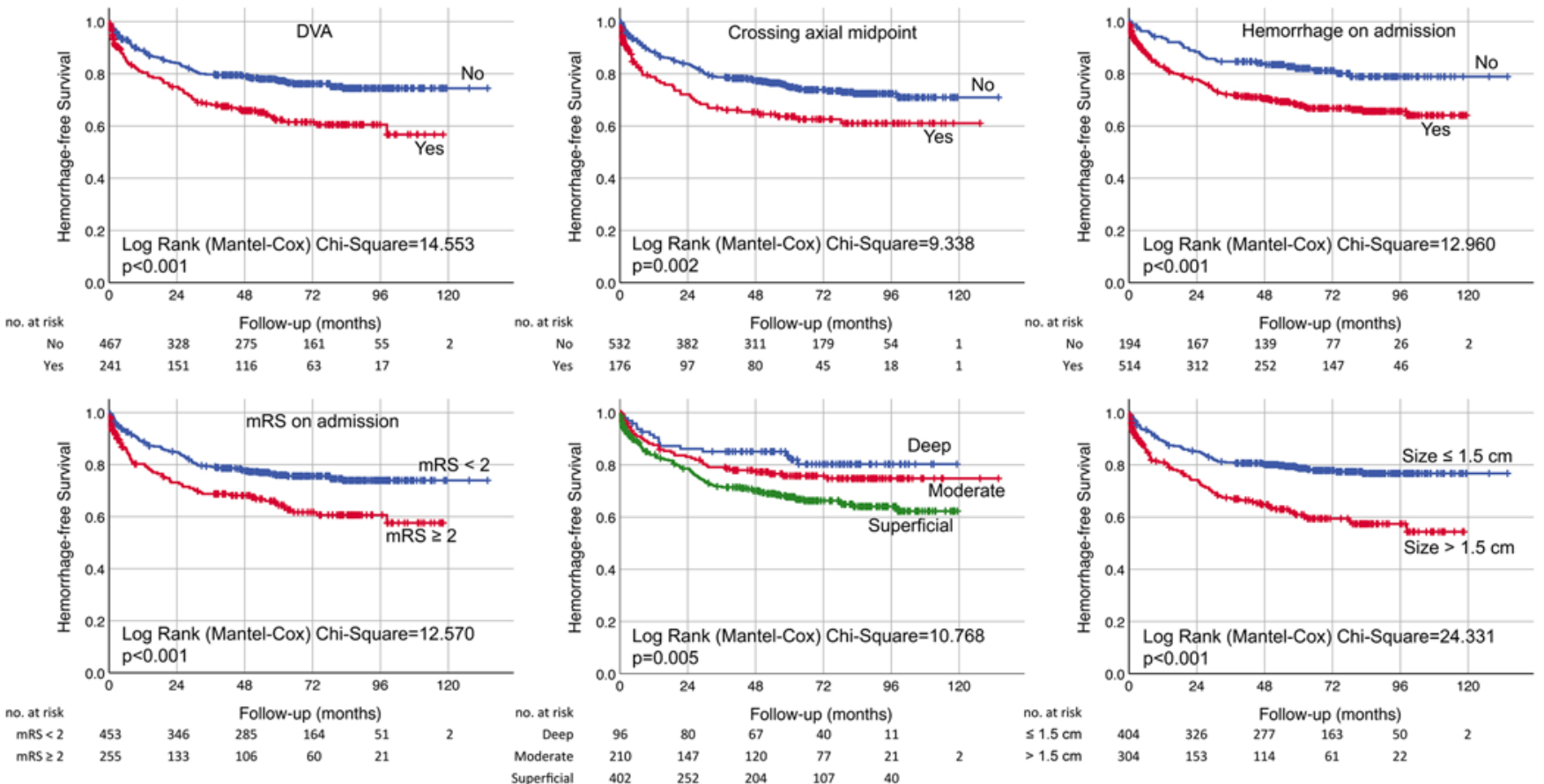

FIG. 5. Kaplan-Meier survival curves showing the risk factors for hemorrhage. DVA, crossing the axial midpoint, hemorrhage on admission, $m R S$ score $\geq 2$ on admission, more superficial location, and lesion size $>1.5 \mathrm{~cm}$ all increased the chance of rehemorrhage. These factors were independent adverse factors in multivariate Cox proportional hazards regression models. The chisquare and $p$ values were estimated by Kaplan-Meier survival analysis. Figure is available in color online only.

rhage, ${ }^{11,27}$ but conversely numerous studies confirmed the insignificance of DVA in predicting hemorrhage, probably due to all CMs containing DVAs., ${ }^{4,913,14,17,23}$ The percentage of trackable radiographic DVAs, ranging from $9 \%$ to $27.7 \%$, was considered an underestimation on conventional radiological sequences. Given the assumption of the existence of occult DVA with minor vessels, the blood flow volume was smaller compared to trackable DVA, and the trackable DVA with relatively greater vessel and slower blood flow took charge of the venous drainage surrounding CMs and had a proclivity for thrombus formation. ${ }^{37}$ The venous drainage obstruction due to occlusion of a trackable DVA could not be easily compensated via shunting to adjacent veins followed by hemorrhagic infarcts, and these catastrophic events might be less likely to occur after occlusion of a minor vessel, which had minor responsibility for drainage. Therefore, the morphology of DVAs and the spatial relationship between DVAs and CMs should be taken into account as potential risk factors that require further study to validate the hypothesis.

Jeon et al. ${ }^{17}$ reported that Zabramski type I/II CMs increased the chance of rehemorrhage compared to type III. ${ }^{36}$ However, in other studies, the MR signal appearance did not have an impact on rehemorrhage. , $^{93,24,34}$ Gross and $\mathrm{Du}^{13}$ argued that the Zabramski grade, almost by definition, was confounded by hemorrhage and subject to interobserver variability. ${ }^{26}$ Otherwise, the MR signal quite depended on the period between symptoms and MRI, which would change over time. Lesion size $\left(\geq 10 \mathrm{~mm}^{21}\right.$ and $20 \mathrm{~mm}^{24}$ ) was significant in only 2 prior studies, and we found that size $>1.5 \mathrm{~cm}$ based on the ROC curve, which produced mass effect given the small volume of the brainstem, predicted rehemorrhage $(p=0.026)$. Lesions crossing the axial midpoint and $\mathrm{mRS}$ scores $\geq 2$, which were associated with lesion size $(p<0.001)$ via bivariate correlation analysis (Fig. 4), were independent risk factors in our cohorts due to the considerable lesion size and poor neurological status on admission, respectively, that conformed to surgical indications.

\section{Hemorrhage Rate}

The annual hemorrhage rate of CCMs was reported to be $0.25 \%,{ }^{8} 1.7 \%,{ }^{7}$ and $2.3 \%-2.5 \%{ }^{19}$ in retrospective studies, and $0.5 \%,{ }^{4} 1.6 \%-3.1 \%,{ }^{9,20,28,29,32}$ and $10.0 \%{ }^{1}$ in prospective studies. Gross and $\mathrm{Du}^{13}$ pooled 7 prior prospective studies $^{1,4,9,20,28,29,32}$ and calculated an annual hemorrhage rate of $2.5 \%$ per patient-year for CCMs (136 bleeds/5081.2 patient-years). These annual rates were susceptible to the composition of the patient population, ${ }^{24}$ and we found that studies with the lowest annual rates of $0.5 \%,{ }^{4} 0.6 \%,{ }^{22}$ and $0.7 \%$ per lesion-year ${ }^{31}$ had the longest mean observation duration (8.8 years), the highest proportion of asymptomatic patients $(100 \%)$, and the lowest proportion of patients with hemorrhagic presentation $(9.1 \%)$, respectively. Taslimi et al. ${ }^{33}$ suggested brainstem location as a source of heterogeneity, and the percentage of brainstem CMs should account for the diversity of hemorrhage rates.

In a retrospective study by Kupersmith et al. ${ }^{21}$ including 37 cases of brainstem CMs, the annual bleeding and rebleeding rates were $2.46 \%$ and $5.1 \%$, respectively. Similar results were also cited by Cantu et al. ${ }^{7}$ (2.33\% in 25 pa- 
tients) and Kondziolka et al. ${ }^{20}$ (2.4\% in 43 patients, which increased to $5.0 \%$ if restricted to brainstem location with prior hemorrhage), and a relatively higher annual hemorrhage rate reported by Gross et al. ${ }^{14}(16.7 \%)$. It should be noted that the annual rebleeding rate in patients with extralesional bleeding could increase to $14.2 \%,{ }^{21}$ and Aiba et al. ${ }^{1}$ reported an annual hemorrhage rate up to $21.5 \%$ in 15 cases of brainstem CMs with hemorrhagic presentation. In our patients with prior hemorrhage $(n=690)$, the annual hemorrhage rate within the 1st year was $18.1 \%$ (95\% CI 15.1\%-21.6\%; 104 bleeds/574.7 patient-years), remarkably similar to the $18.3 \%$ rate in 74 patients presenting with acute hemorrhage reported by Flemming et al. ${ }^{9}$ notwithstanding location. In patients with 1 prior hemorrhage $(n=455)$, the annual hemorrhage rate was 6.0\% (141 bleeds/2342.0 patient-years), which was also similar to the overall annual hemorrhage rate for patients with hemorrhagic presentation $(6.19 \%){ }^{9}$ Our overall annual hemorrhage rate $(7.0 \%)$ was close to that of thalamic CMs (9.7\%) in a previous study. ${ }^{34}$ Temporal clustering of hemorrhage within the first 2 years has been observed in several studies $^{4,6,9,13}$ and the hemorrhage risk decreased thereafter, comparable to our overall cohort with a $17.5 \%$ /patient-year rate within the 1st year and 4.7\%/patient-year rate thereafter. If patients were followed up for the rest of their lives, the annual hemorrhage rate would decrease even if the $\mathrm{CM}$ involved eloquent locations. Given the phenomenon of temporal clustering of hemorrhage and that the majority of the patients presented with hemorrhage, the true hemorrhage rate was likely overestimated in our study. The annual hemorrhage rate of patients with or without hemorrhagic presentation was $8.3 \%$ and $4.3 \%$, and the annual hemorrhage rates of patients with $>1,1$, or no prior ictus were $9.9 \%, 6.0 \%$, and $1.0 \%$, respectively (Table 2 ). These results indicate that the hemorrhage rate was vulnerable to patient composition and clinical presentation models.

\section{Implications for Clinical Management}

There were several significantly different clinical parameters between the subgroups of surgery and SRS, which might lead to the large disparity in untreated observation intervals between both groups (Table 3 ). The surgery subgroup had significantly younger age, higher retrospective annual hemorrhage rate, larger lesion size, more lesions crossing the axial midpoint and being superficially seated, and worse mRS score at censoring than that of the SRS subgroup. Remarkably, the surgery subgroup had a significantly higher annual prospective hemorrhage rate $(70.9 \%$ vs $10.6 \%$ ), worse hemorrhage-free survival by Kaplan-Meier analysis (log-rank test, chi-square $=17.161, \mathrm{p}<0.001$ ), and shorter estimated median hemorrhage-free survival time (10.7 months), which was not reached in the SRS subgroup and mainly contributed to the large disparity.

We focused on symptomatic hemorrhage, which was easily detected with pertinent radiographs, and because new or aggravated symptoms would remind patients to undergo immediate radiological examination to obtain the radiological evidence and definitively confirm the hemorrhage. This convincing information helped to adjust the individualized patient management strategy. Clinical exacerbation due to hemorrhage rather than ischemia justi- fied resection. However, asymptomatic hemorrhage, which almost always was unnoticed with a small volume of hematoma, was less likely detected unless it occurred just before a scheduled radiological examination. Because it was asymptomatic, we were less likely to detect and record all asymptomatic hemorrhage, even with real-time radiological monitoring; therefore, the number of asymptomatic hemorrhages was usually underestimated. It would significantly increase medical costs to find all asymptomatic hemorrhages via frequent radiological examinations. Most importantly, given the assumption of asymptomatic hemorrhage, for which the management strategy (observation) was likely unchanged, resection was controversial and seemed to be excessive treatment if the risk outweighed the benefit. In addition, the surgical morbidity might be less acceptable because the preoperative neurological status was normal. Therefore, the evaluation of the incidence of asymptomatic hemorrhage appeared to be a paradox, because it was barely possible to capture all asymptomatic ones, and the incorrect questionable hemorrhage rate would misguide the clinical consultation. It was reasonable for us to wait for the asymptomatic hemorrhage to become a symptomatic one that would convince the patient to shift his/her attitude toward treatment.

We would recommend surgery to patients meeting surgical indications but would not suggest prophylactic resection to eliminate future hemorrhage in nonsurgical candidates, because of the potential surgical morbidity and because we could not guarantee the absolute accuracy of predicting future hemorrhage at enrollment. The aggressive attitude became less feasible in routine clinical practice if the surgeon could not accurately judge whether rehemorrhage was possible or not. Repeated hemorrhages with new FND within a short period of time implied clinical progression and the aggressive nature of the lesions that to a certain extent warranted surgical intervention; however, other parameters (e.g., location, depth, accessibility, and size) should be considered as well, and it remained important to distinguish aggressive ones from occult/silent ones.

\section{Study Limitations}

This study was a hospital-based consecutive cohort with significant systematic referral bias and was susceptible to random sampling of patients from the general population. The selection bias was unavoidable given that severe brainstem CMs with a more aggressive course justifying surgery were excluded from the study and the management strategy for these lesions was less debatable, but the remaining patients in the present cohort with weaker indications for surgery or who declined surgery were precisely those requiring our attention to investigate their hemorrhagic risk and determine a reasonable treatment. As a national medical referral center, our results might overestimate the hemorrhage rate compared to that of the general population, ${ }^{24}$ but they may be useful to a certain degree for other tertiary hospitals that often encounter patients with hemorrhagic presentation transferred from primary care providers or secondary hospitals. A population-based multicenter study is needed to reduce these biases and improve the generalization and extrapolation to a broader patient population. ${ }^{4,5}$ 


\section{Conclusions}

In this study, we reported an annual hemorrhage rate of $7.0 \%$ exclusively for brainstem CMs, which significantly increased if patients presented with other risk factors. Patients with hemorrhagic presentation needed close followup regardless of the number of prior hemorrhages. Our results are useful for patients and physicians in helping to select a personalized treatment in other referral centers. The referral bias and the composition of the patient population of our cohort should be noted, and a populationbased multicenter study is suggested to reduce these limitations. Further studies are required to verify our findings.

\section{Acknowledgments}

The study was supported by Beijing Municipal Science \& Technology Commission (grant no. Z171100001017067) and Capital's Funds for Health Improvement and Research (grant no. CFH 2018-2-2043).

\section{References}

1. Aiba T, Tanaka R, Koike T, Kameyama S, Takeda N, Komata $\mathrm{T}$ : Natural history of intracranial cavernous malformations. J Neurosurg 83:56-59, 1995

2. Al-Holou WN, O’Lynnger TM, Pandey AS, Gemmete JJ, Thompson BG, Muraszko KM, et al: Natural history and imaging prevalence of cavernous malformations in children and young adults. J Neurosurg Pediatr 9:198-205, 2012

3. Al-Shahi Salman R, Berg MJ, Morrison L, Awad IA: Hemorrhage from cavernous malformations of the brain: definition and reporting standards. Stroke 39:3222-3230, 2008

4. Al-Shahi Salman R, Hall JM, Horne MA, Moultrie F, Josephson CB, Bhattacharya JJ, et al: Untreated clinical course of cerebral cavernous malformations: a prospective, populationbased cohort study. Lancet Neurol 11:217-224, 2012

5. Al-Shahi Salman R, Kitchen N, Thomson J, Ganesan V, Mallucci C, Radatz M: Top ten research priorities for brain and spine cavernous malformations. Lancet Neurol 15:354-355, 2016

6. Barker FG II, Amin-Hanjani S, Butler WE, Lyons S, Ojemann RG, Chapman PH, et al: Temporal clustering of hemorrhages from untreated cavernous malformations of the central nervous system. Neurosurgery 49:15-25, 2001

7. Cantu C, Murillo-Bonilla L, Arauz A, Higuera J, Padilla J, Barinagarrementeria F: Predictive factors for intracerebral hemorrhage in patients with cavernous angiomas. Neurol Res 27:314-318, 2005

8. Del Curling O Jr, Kelly DL Jr, Elster AD, Craven TE: An analysis of the natural history of cavernous angiomas. J Neurosurg 75:702-708, 1991

9. Flemming KD, Link MJ, Christianson TJ, Brown RD Jr: Prospective hemorrhage risk of intracerebral cavernous malformations. Neurology 78:632-636, 2012

10. Garcia RM, Ivan ME, Lawton MT: Brainstem cavernous malformations: surgical results in 104 patients and a proposed grading system to predict neurological outcomes. Neurosurgery 76:265-278, 2015

11. Gross BA, Batjer HH, Awad IA, Bendok BR: Brainstem cavernous malformations. Neurosurgery 64:E805-E818, 2009

12. Gross BA, Du R: Cerebral cavernous malformations: natural history and clinical management. Expert Rev Neurother 15:771-777, 2015

13. Gross BA, Du R: Hemorrhage from cerebral cavernous malformations: a systematic pooled analysis. J Neurosurg 126:1079-1087, 2017

14. Gross BA, Du R, Orbach DB, Scott RM, Smith ER: The nat- ural history of cerebral cavernous malformations in children. J Neurosurg Pediatr 17:123-128, 2016

15. Gross BA, Lin N, Du R, Day AL: The natural history of intracranial cavernous malformations. Neurosurg Focus 30(6):E24, 2011

16. Horne MA, Flemming KD, Su IC, Stapf C, Jeon JP, Li D, et al: Clinical course of untreated cerebral cavernous malformations: a meta-analysis of individual patient data. Lancet Neurol 15:166-173, 2016

17. Jeon JS, Kim JE, Chung YS, Oh S, Ahn JH, Cho WS, et al: A risk factor analysis of prospective symptomatic haemorrhage in adult patients with cerebral cavernous malformation. $\mathbf{J}$ Neurol Neurosurg Psychiatry 85:1366-1370, 2014

18. Kalani MY, Zabramski JM: Risk for symptomatic hemorrhage of cerebral cavernous malformations during pregnancy. J Neurosurg 118:50-55, 2013

19. Kim DS, Park YG, Choi JU, Chung SS, Lee KC: An analysis of the natural history of cavernous malformations. Surg Neurol 48:9-18, 1997

20. Kondziolka D, Lunsford LD, Kestle JR: The natural history of cerebral cavernous malformations. J Neurosurg 83:820 824, 1995

21. Kupersmith MJ, Kalish H, Epstein F, Yu G, Berenstein A, Woo H, et al: Natural history of brainstem cavernous malformations. Neurosurgery 48:47-54, 2001

22. Labauge P, Brunereau L, Laberge S, Houtteville JP: Prospective follow-up of 33 asymptomatic patients with familial cerebral cavernous malformations. Neurology 57:1825-1828, 2001

23. Li D, Hao SY, Jia GJ, Wu Z, Zhang LW, Zhang JT: Hemorrhage risks and functional outcomes of untreated brainstem cavernous malformations. J Neurosurg 121:32-41, 2014

24. Li D, Hao SY, Tang J, Xiao XR, Jia GJ, Wu Z, et al: Clinical course of untreated pediatric brainstem cavernous malformations: hemorrhage risk and functional recovery. J Neurosurg Pediatr 13:471-483, 2014

25. Li D, Hao SY, Tang J, Xiao XR, Jia GJ, Wu Z, et al: Surgical management of pediatric brainstem cavernous malformations. J Neurosurg Pediatr 13:484-502, 2014

26. Li D, Jiao YM, Wang L, Lin FX, Wu J, Tong XZ, et al: Surgical outcome of motor deficits and neurological status in brainstem cavernous malformations based on preoperative diffusion tensor imaging: a prospective randomized clinical trial. J Neurosurg 130:286-301, 2018

27. Li D, Yang Y, Hao SY, Wang L, Tang J, Xiao XR, et al: Hemorrhage risk, surgical management, and functional outcome of brainstem cavernous malformations. J Neurosurg 119:996-1008, 2013

28. Moriarity JL, Wetzel M, Clatterbuck RE, Javedan S, Sheppard JM, Hoenig-Rigamonti K, et al: The natural history of cavernous malformations: a prospective study of 68 patients. Neurosurgery 44:1166-1173, 1999

29. Porter PJ, Willinsky RA, Harper W, Wallace MC: Cerebral cavernous malformations: natural history and prognosis after clinical deterioration with or without hemorrhage. J Neurosurg 87:190-197, 1997

30. Rigamonti D, Drayer BP, Johnson PC, Hadley MN, Zabramski J, Spetzler RF: The MRI appearance of cavernous malformations (angiomas). J Neurosurg 67:518-524, 1987

31. Robinson JR, Awad IA, Little JR: Natural history of the cavernous angioma. J Neurosurg 75:709-714, 1991

32. Schneble HM, Soumare A, Hervé D, Bresson D, Guichard JP, Riant F, et al: Antithrombotic therapy and bleeding risk in a prospective cohort study of patients with cerebral cavernous malformations. Stroke 43:3196-3199, 2012

33. Taslimi S, Modabbernia A, Amin-Hanjani S, Barker FG II, Macdonald RL: Natural history of cavernous malformation: systematic review and meta-analysis of 25 studies. Neurology 86:1984-1991, 2016 
34. Tian KB, Zheng JJ, Ma JP, Hao SY, Wang L, Zhang LW, et al: Clinical course of untreated thalamic cavernous malformations: hemorrhage risk and neurological outcomes. J Neurosurg 127:480-491, 2017

35. Wang CC, Liu A, Zhang JT, Sun B, Zhao YL: Surgical management of brain-stem cavernous malformations: report of 137 cases. Surg Neurol 59:444-454, 2003

36. Zabramski JM, Wascher TM, Spetzler RF, Johnson B, Golfinos J, Drayer BP, et al: The natural history of familial cavernous malformations: results of an ongoing study. J Neurosurg 80:422-432, 1994

37. Zuurbier SM, Hickman CR, Tolias CS, Rinkel LA, Leyrer R, Flemming KD, et al: Long-term antithrombotic therapy and risk of intracranial haemorrhage from cerebral cavernous malformations: a population-based cohort study, systematic review, and meta-analysis. Lancet Neurol 18:935-941, 2019

\section{Disclosures}

The authors report no conflict of interest concerning the materials or methods used in this study or the findings specified in this paper.

\section{Author Contributions}

Conception and design: all authors. Acquisition of data: $\mathrm{Li}, \mathrm{Ze}-\mathrm{Yu}$ Wu, Liu, Ma, Huo, Wang. Analysis and interpretation of data: all authors. Drafting the article: $\mathrm{Li}, \mathrm{Ze}-\mathrm{Yu} \mathrm{Wu}$, Liu, Wang. Critically revising the article: all authors. Reviewed submitted version of manuscript: all authors. Approved the final version of the manuscript on behalf of all authors: JT Zhang. Statistical analysis: Li, $\mathrm{Ze}-\mathrm{Yu} \mathrm{Wu}, \mathrm{Liu}, \mathrm{Ma}, \mathrm{Huo}$, Zhen Wu. Administrative/technical/ material support: all authors. Study supervision: JT Zhang, Li, Ze-Yu Wu, Liu, Wang, LW Zhang, Zhen Wu.

\section{Correspondence}

Jun-Ting Zhang: Beijing Tiantan Hospital, Capital Medical University, Beijing, People's Republic of China. zhangjunting2003@ aliyun.com. 